\title{
Arm function after stroke. An evaluation of grip strength as a measure of recovery and a prognostic indicator
}

\author{
ALAN SUNDERLAND, DEBORAH TINSON, LESLEY BRADLEY, \\ RICHARD LANGTON HEWER
}

From the Stroke/Neurological Rehabilitation Unit, Frenchay Hospital, Bristol, UK

SUMMARY The value of strength of voluntary grip as an indicator of recovery of arm function was assessed by testing 38 recent stroke patients using a sensitive electronic dynamometer, and comparing the results with those from five other arm movement and function tests (Motricity Index, Motor Club Assessment, Nine Hole Peg Test, and Frenchay Arm Test). This procedure allowed measurement of grip in a large proportion of patients, and strength correlated highly with performance on the other tests. Measuring grip over a six month follow up period was a sensitive method of charting intrinsic neurological recovery. The presence of voluntary grip at one month indicates that there will be some functional recovery at six months.

Progress in understanding recovery from stroke and assessing the impact of rehabilitation therapy has been limited by the lack of good measures of function. In this context a good measure is one which is reliable, valid and sufficiently sensitive to detect small changes in performance. Also, it should have a wide range of use capable of measuring mild as well as severe impairment. The ideal measure would meet these requirements yet only require a brief and simple assessment procedure. This would allow frequent monitoring to chart the course of recovery.

In a previous study, ${ }^{\prime}$ the available tests of arm function after stroke were reviewed. Four tests were assessed against the above criteria and these were the Frenchay Arm Test, ${ }^{2}$ the Nine Hole Peg Test, ${ }^{3}$ speed of finger tapping, ${ }^{4}$ and measurement of strength of grip. All four were found to be reliable and valid but they varied in their range of use and sensitivity to change. Of particular interest were the results for strength of the grip which showed that it was the best of these measures for detecting early recovery and was useful in predicting the final outcome. These results emerged despite the fact that a mechanical dynamometer was used which had limited sensitivity at the upper and

Correspondence to: Dr Sunderland, Stroke/Neurological Rehabilitation Unit, Frenchay Hospital, Bristol BS16 ILE, UK.

Received 13 January 1989 and in revised form 29 March 1989. Accepted 6 April 1989 lower ends of the range of strength of grip. This paper reports the data collected using an electronic dynamometer with a much wider range of sensitivity. We aimed to investigate to what extent strength of grip meets the criteria of a good measure of recovery of arm function when measured with such an instrument.

Measuring the grip strength of stroke patients has not been widely used as an assessment procedure and indeed has been rejected actively as a method within orthodox physiotherapy. ${ }^{56}$ This rejection has been motivated by two concerns. First, that measuring strength alone ignores the role of impaired co-ordination of muscle groups in producing deficient motor performance. Second, it has been argued that because an increase in finger flexion is part of the spastic pattern which typically evolves after stroke, ${ }^{78}$ increased grip might indicate this spasticity rather than any improvement in muscle control. On the other hand there is ample evidence to show that weakness is one of the primary components of hemiplegia ${ }^{910}$ which improves with functional recovery. ${ }^{1}$ This study investigated the relationship between grip strength, spasticity and functional recovery to discover whether in fact it may be a valuable marker of recovery in the typical stroke patient.

\section{Method}

Patients

All stroke patients admitted to our hospital with unilateral 
deficits are screened with the Nine Hole Peg Test (NHPT) to select those with a significant loss of arm function still present three weeks after stroke, who are also suitable for active rehabilitation.

Significant loss of function is defined as taking more than 18 seconds to place all nine pegs with the affected hand (95th percentile for the normal elderly), ${ }^{\prime}$ and suitability for active rehabilitation is defined as the ability to complete the peg test with the unaffected hand within a generous time limit of 30 seconds. This excludes patients who are very drowsy or who have very severe cognitive deficits. During one year, 38 patients were selected on this basis; 17 men and 21 women (mean age 67, range, 31-82 years). All except one were formerly right handed. In 21 cases the left arm was affected, and in 17 the right arm. In 36 cases, neurological signs were consistent with a stroke affecting the territory of the middle cerebral artery (confirmed by CT in 18 cases). There were two brainstem strokes.

This sample of patients took part in the initial stage of a trial of intensive therapy for arm function. ${ }^{11}$ This paper concerns only the assessment procedures used and does not investigate any effects due to varying intensity of therapy. These will be reported in a later paper when the treatment trial is complete.

\section{Measurement procedures}

Grip strength was assessed using an electronic dynamometer (MIE Medical Research, Digital Pinch/Grip Analyser). This consists of two flat padded bars mounted parallel to each other $2 \mathrm{~cm}$ apart. When these are squeezed together the maximum force is indicated on a digital display which registers from 1 to 400 Newtons (that is, from light touch to heavy pressure). The dynamometer is designed to record accurately the pressure exerted on the bars irrespective of the point of grip along their length. However, the resistance to movement changes noticeably depending on the exact position, with greater springiness apparent when the bars are gripped at their very end. For this reason, a standardised position of grip was used in this study. The patient was seated with the hand resting comfortably in the lap. The dynamometer was placed with a marked point on one bar against the web of skin between the thumb and index finger. The digital display was then set to zero, thus discounting any resting pressure exerted by the patient due to involuntary flexion of the fingers. The patient was told to squeeze as hard as possible and then release. The dynamometer was positioned so that the patient was not able to see the digital display and no verbal feedback was given on performance. This procedure was repeated three times with each hand, alternating between the affected and unaffected side.

Four additional tests of arm movement and function were used:

(1) Motricity Index..$^{12}$ With the patient seated, power and range of active movement are rated for shoulder abduction, elbow flexion, and pinch between the thumb and index finger. Each movement is rated on a 5-point scale. The points on the scales are given weighted scores to reflect the significance of each point on the scale as a proportion of total recovery. A total score is then calculated for the three movements.

(2) Motor Club Assessment.$^{13}$ Range of active movement is rated for shoulder shrugging, arm lifting, forearm supination, wrist cocking, and finger extension. Each movement is rated on a 3 -point scale $(0=$ no movement, $1=$ limited $Z$ movement, 2 = full range of movement).

(3) Frenchay Arm Test. ${ }^{2}$ This assesses the ability to carry out functional tasks with the affected hand. The patient is scored pass or fail on each of five tasks: stabilising a ruler, picking up a $12 \mathrm{~mm}$ diameter cylinder, picking up and $\mathscr{T}$ drinking from a glass tumbler, removing and replacing a $\bigcirc$ clothes peg positioned on a vertical dowel, and picking up a comb and combing sides and back of head.

(4) Nine Hole Peg Test. ${ }^{3}$ A test of manual dexterity. The patient is asked to pick up nine dowels from a tray at table height and place them as quickly as possible into nine holes in a neighbouring horizontal board. There is a time limit of 50 seconds for each trial. Three trials were given with each hand, alternating between the affected and unaffected side. Results are expressed as number of pegs placed per second.

Sensation was assessed using five clinical procedures:

(1) The patient was asked to report when they were touched on the back of the hand.

(2) The procedure was then repeated with simultaneous touch to both hands to test for sensory extinction. ${ }^{14}$

(3) The patient was then asked if there was a subjective difference between sensations from affected and unaffected hand.

(4) Proprioception in the thumb was assessed by moving iv the tip of thumb up or down approximately $2 \mathrm{~cm}$ and asking $\overrightarrow{.}$ the patient to report the direction of movement. Number correct out of four trials was recorded.

(5) Proprioception for gross movement was assessed wit the thumb-finding test. ${ }^{15}$ The affected arm was passivelof moved and the patient asked to grasp the thumb with the unaffected hand. A 5-point rating scale was used to recor $z$ accuracy of movement.

The patient had eyes closed or wore a blindfold during these sensory tests.

Spasticity was assessed by passive movement of the shoulder, elbow and wrist. Abnormal resistance to movement was rated as absent, mild or severe at each joint.

Assessment points Patients had an Initial Assessment within three weeks of their stroke or as soon as possible thereafter (mean $=11$ days after stroke, $S D=9$ ), and the procedures were repeated at one month (mean $=35$ days, SD $=10)$, three months (mean $=101$ days, $S D=19$ ) and six months $($ mean $=193$ days, $S D=16)$

\section{Results}

Dynamometer scores from the initial assessment were inspected to discover the method of analysis which would give least variation in performance. Scores from single attempts with the affected hand produced considerable variation (coefficients of variation of 172,171 and 172 for the three trials). Taking the average for the three trials reduced the variation only slightly (coefficient of variation $=169$ ) but a much less variable score was achieved by expressing the average strength of grip on the affected side as a percentage of the average grip on the unaffected side (coefficient of variation $=146$ ). This percentage grip measure provides some control for the wide variations in strength which exist in the normal elderly population, ${ }^{1}$ 
Table 1 Mean scores and range of use for the five motor tests at the initial assessment point $(n=38)$

\begin{tabular}{|c|c|c|c|c|c|}
\hline & $\begin{array}{l}\text { Grip } \\
\text { Strength } \\
\text { (Percentage of } \\
\text { unaffected side) }\end{array}$ & $\begin{array}{l}\text { Motricity } \\
\text { Index } \\
\text { (Total out } \\
\text { of 100) }\end{array}$ & $\begin{array}{l}\text { Motor Club } \\
\text { Assessment } \\
\text { (Total out } \\
\text { of 10) }\end{array}$ & $\begin{array}{l}\text { Frenchay Arm } \\
\text { Test } \\
\text { (Total out } \\
\text { of 5) }\end{array}$ & $\begin{array}{l}\text { 9-Hole Peg } \\
\text { Test } \\
\text { (Pegs per } \\
\text { second) }\end{array}$ \\
\hline $\begin{array}{l}\text { Mean } \\
\text { (SD) } \\
\text { Unassessable cases }\end{array}$ & $\begin{array}{c}18 \\
(27) \\
0\end{array}$ & $\begin{array}{c}34 \\
(36) \\
0\end{array}$ & $\begin{array}{c}3 \cdot 3 \\
(3 \cdot 7) \\
3\end{array}$ & $\begin{array}{c}1 \cdot 1 \\
(1 \cdot 9) \\
1\end{array}$ & $\begin{array}{c}0 \cdot 03 \\
(0 \cdot 7) \\
1\end{array}$ \\
\hline Cases scoring zero & 17 & 16 & 14 & 25 & 29 \\
\hline Cases with normal* scores & 2 & 1 & 3 & 6 & 0 \\
\hline Cases in mid-ranget & $\begin{array}{l}19 \\
(50 \%)\end{array}$ & $\stackrel{21}{(55 \%)}$ & $\begin{array}{l}18 \\
(47 \%)\end{array}$ & $\stackrel{6}{(15 \%)}$ & $\begin{array}{c}8 \\
(21 \%)\end{array}$ \\
\hline
\end{tabular}

NOTE: * "Normal" scores were defined as follows: Motricity Index, Motor Club and Frenchay Arm Test - full marks. Percentage grip $75 \%$ regardless of dominance (see previous study)'. Nine-Hole Peg Test -0.5 pegs per second or greater (see previous study) ${ }^{\prime}$.

t"Mid-range" = above zero but not normal.

and this score is used throughout all subsequent analysis in this paper.

Table 1 summarises the results for the five motor tests at the Initial Assessment.

\section{Range of Use}

Table 1 shows that $55 \%$ of patients had measurable grip at the Initial Assessment, and only $5 \%$ (two cases) had scores within the normal range. This range of use is slightly poorer but comparable to the Morticity Index ( $57 \%$ above zero, $2 \%$ normal). In contrast, the Frenchay Arm Test and the NHPT both suffer from floor effects, with over $65 \%$ of cases scoring zero.

\section{Sensitivity to Change}

Seven patients were lost to follow-up over the subsequent six months (four died, one refused to participate, one left the district, and one developed an unrelated illness). The figure shows the mean scores

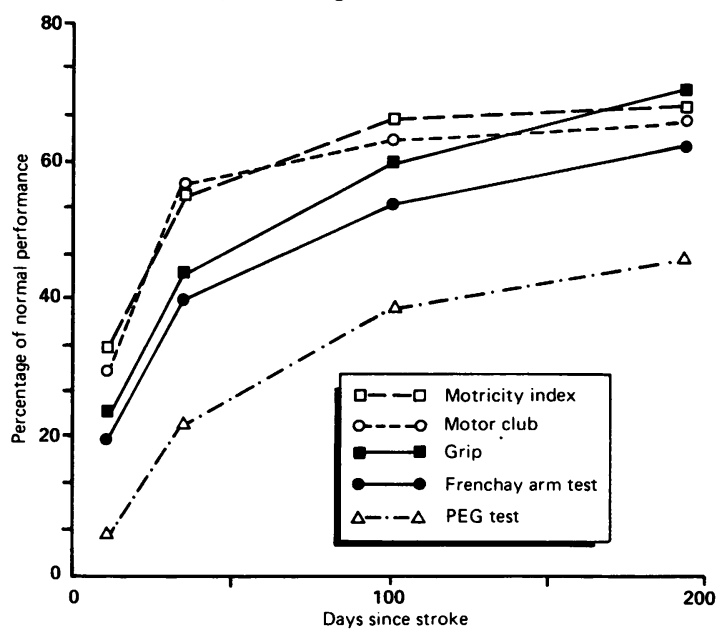

Fig Mean scores at each assessment point for the five motor tests. for the remaining 31 patients over the four assessment points. As expected, all five motor tests produced a recovery curve with a fast initial rise, but only slight improvement between 3 and 6 months after a stroke.

Making comparisons between these five curves is not a good way to investigate the sensitivities of these tests, because the shape of the curves is influenced by differences in scaling. Also, these mean scores hide large individual differences in the pattern of recovery. The best way to compare the tests is therefore to look at the number of patients who showed improvements between each pair of adjoining assessment points (see table 2). This shows that the Motricity Index is the most sensitive in detecting early recovery. However, only percentage grip strength and the peg test showed increases in a statistically significant proportion of cases between each pair of assessments, and the former showed these changes in a larger number of patients.

\section{Validity}

At the initial assessment, percentage grip correlated highly with the Motricity Index $(r=0.87)$, Frenchay Arm Test $(r=0.86)$, and Motor Club Assessment $(r=0.81)$. The correlation with the Peg Test was somewhat weaker $(r=0.71)$. This may in part have

Table 2 Comparison of the sensitivity of the five motor tests. Number of cases where scores increased between adjoining assessments $(n=31)$

\begin{tabular}{llll}
\hline & \multicolumn{4}{l}{ Assessment period } \\
\cline { 2 - 4 } & $\begin{array}{llll}\text { Initial- } \\
\text { l month }\end{array}$ & $\begin{array}{c}\text { l month- } \\
\text { 3 months }\end{array}$ & $\begin{array}{c}3 \text { months- } \\
6 \text { months }\end{array}$ \\
\hline Grip Strength & $18 \dagger$ & $16^{*}$ & $19^{*}$ \\
Motricity Index & $22 \dagger$ & $22 \dagger$ & 9 \\
Motor Club & $20 \dagger$ & $12^{*}$ & 5 \\
Frenchay Arm Test & $12^{*}$ & $11^{*}$ & 6 \\
9-Hole Peg Test & $12^{*}$ & $16^{*}$ & $14^{*}$ \\
\hline
\end{tabular}

NOTE: Significance of increases for sample as a whole were tested using Wilcoxon matched-pairs tests ${ }^{*} p<0.01$, tp $<0.001$, one tailed. 
Table 3 The relationship between percentage grip, Peg Test performance, and impaired sensation at the 6 month assessment $(n=31)$

\begin{tabular}{llll}
\hline & \multicolumn{3}{l}{ Percentage Grip } \\
\cline { 2 - 4 } & Zero & $\begin{array}{l}\text { Impaired } \\
<75 \%\end{array}$ & Normal \\
\hline $\begin{array}{l}\text { Peg Test } \\
\text { Normal } \\
\text { Impaired (<0.5 pegs/s) }\end{array}$ & - & $1(0)$ & $3(0)$ \\
Zero & $-6(4)$ & $6(1)$ & $8(5)$ \\
\hline
\end{tabular}

NOTE: The number of cases with deficits on at least one measure of sensation is shown in brackets.

been due to the large number of cases scoring zero on the Peg Test at this assessment point. However, at the final assessment when there was less of a floor effect, the weakest correlation to percentage grip was still the Peg Test (Motricity Index, $r=0.83$; Frenchay Arm Test, $r=0.90 ;$ Motor Club Assessment, $r=0.86 ;$ Peg Test, $r=0.79$ ). This weakest relationship is explored in table 3 which shows that seven patients had recordable grip but could not attempt the more difficult Peg Test, and in eight cases percentage grip was within the normal range but performance was impaired on the Peg Test. Five of these eight cases had impaired sensation which may have accounted for their poor performance despite normal grip, as sensation was normal in all patients who achieved normal scores on the Peg Test.

The relationship between spasticity and grip was investigated. At the initial assessment, 12 patients $(31 \%)$ were rated as having abnormal resistance to passive movement at the shoulder, elbow or wrist. Only four of these 12 had any measurable grip (scores of $24,15,13$ and $4 \%$ ). Amongst the 31 patients followed over 6 months, $7(22 \%)$ showed increasing resistance to passive movement. Again, four of these had no measurable grip even at 6 months. The remaining three cases all showed increasing scores on the Motricity Index and Motor Club Assessment, and grip test, showing that increases in grip paralleled improving function in these cases. A similar picture emerges when the changes in function are analysed for all 22 patients who showed any increase in grip over the six months. None of these 22 showed any deterioration in function as assessed by the Frenchay Arm Test (16 improved, and six remained the same). This suggests that in every case improvements in grip strength were associated with improving function and not just increasing spasticity.

\section{Prognosis}

Using scores from the one month assessment, the five motor tests were compared in their ability to predict functional outcome at six months. Table 4 shows the cut-off scores for each test which allowed the maximum number of patients to be correctly classified into those who would eventually score above zero on the Frenchay Arm Test, and those who would not. Zero grip at one month indicated no future return of function in all but one case. This accuracy of prognosis was only improved by the Motricity Index, which gave perfect prediction of outcome at six months.

\section{Discussion}

The patients who took part in this study formed a small but representative sample of recent stroke patients with impaired arm function. The measurement of grip strength with an electronic dynamometer proved to be a procedure which was brief but which nonetheless largely met the criteria for a good measure of function which were outlined at the start of this paper. It has a wide range of use, allowing the assessment of both severely and mildly impaired patients. It showed good sensitivity to change, detecting early recovery as well as later changes three to six

Table 4 Prediction of functional outcome. Classification of cases using cut-off scores at the 1 month assessment

\begin{tabular}{|c|c|c|c|c|}
\hline \multirow[b]{2}{*}{ Test } & \multirow{2}{*}{$\begin{array}{l}\text { Cut-off score at } \\
\text { l month }\end{array}$} & \multicolumn{2}{|c|}{ Frenchay Arm Test at 6 months } & \multirow[b]{2}{*}{ Cases wrongly classified } \\
\hline & & Cases scoring zero & Cases above zero & \\
\hline Percentage Grip & $\begin{array}{r}>0 \\
0\end{array}$ & $\begin{array}{l}0 \\
8\end{array}$ & $\begin{array}{r}21 \\
1\end{array}$ & $3 \%$ \\
\hline Motricity Index & $\begin{array}{l}>18 / 100 \\
<18 / 100\end{array}$ & $\begin{array}{l}0 \\
8\end{array}$ & $\begin{array}{r}22 \\
0\end{array}$ & 0 \\
\hline Motor Club & $\begin{array}{l}>2 / 10 \\
<2 / 10\end{array}$ & $\begin{array}{l}0 \\
8\end{array}$ & $\begin{array}{r}21 \\
1\end{array}$ & $3 \%$ \\
\hline Frenchay Arm Test & $\begin{array}{r}>0 \\
0\end{array}$ & $\begin{array}{l}0 \\
8\end{array}$ & $\begin{array}{r}17 \\
4\end{array}$ & $13 \%$ \\
\hline 9-Hole Peg Test & $\begin{array}{r}>0 \\
0\end{array}$ & $\begin{array}{l}0 \\
8\end{array}$ & $\begin{array}{r}14 \\
8\end{array}$ & $27 \%$ \\
\hline
\end{tabular}


months after stroke. Amongst the other tests used in this study, the Motricity Index had the advantage of simplicity and wide range of use. However, it was unable to detect small, late improvements which were indicated by increasing grip strength between the final two assessment points. Also, improvements in grip strength closely paralleled improvements on more complex motor tasks, suggesting that although a simple function in itself, strength of grip can be used as an index of recovery of arm function more generally.

Recovery in the hemiplegic arm normally has a proximal to distal gradient, with movement at the shoulder or elbow returning first and finger movements recovering last, if at all. ${ }^{7.8}$ It was therefore surprising to find that nearly as large a proportion of patients achieved scores on the dynamometer as had above zero scores on the Motricity Index which includes ratings of movement or muscle contraction at the shoulder or elbow. This was almost certainly due to the objective and sensitive nature of the grip assessment procedure. Even the tiniest flicker of voluntary grip was registered by the electronic dynamometer, whereas detection of early recovery at the shoulder or elbow was based on a difficult and skilled judgement of whether there were palpable muscle contractions.

It has been asserted that strength of grip in the stroke patient might not indicate voluntary motor control because it would be difficult to distinguish voluntary grasp from spastic flexion of the fingers. ${ }^{6}$ This did not appear to be the case given the procedure used in the present study, where grip was measured as an increase above the resting baseline for the individual patient. Under these conditions, the majority of patients with definite spasticity were shown to be incapable of producing any additional voluntary grasp. In the cases where there was voluntary movement despite spasticity, improving grip strength was always accompanied by improvements in voluntary arm movement out of the spastic pattern. So, while we cannot exclude the possibility that spasticity might contribute to grip strength in some cases, this study suggests that if there is such a contribution it must be small, and does not invalidate this measure as an index of voluntary function.

A second reason which has been given for not using measures of strength in the assessment of motor recovery after stroke, is that they do not provide information about the deficits in selective control and co-ordination of agonist and antagonist muscle groups. It has been argued that these deficits, together with spasticity, are the major factors in hemiplegia and that apparent reductions in strength are secondary to these problems. ${ }^{5,16}$ However, although poor motor control and co-ordination are factors, ${ }^{17}$ physiological studies have shown that weakness is a separate primary problem in the spastic as well as the flaccid patient. Upper motor neuron lesions result in a decrease in the number of motor units recruited during voluntary movement, ${ }^{18}$ and a reduction in the firing rate of those which are recruited. ${ }^{19}$ The functional ability of the hemiparetic stroke patient is therefore at least partly determined by how successfully he can generate sufficient power to allow free movement of the arm. Strength of grip may be a general indication of the degree of weakness in the arm, and this may underlie the correlation between this measure and performance on more complex motor tasks.

There are, of course, limits to the usefulness of such a general measure of power. Strength of grip did not correlate well with manual dexterity on the Nine Hole Peg Test, where patients with sensory loss did poorly despite normal strength. This confirms the argument that assessment of the arm should not be based on a single measure, but should include a selection of tests of sensation, co-ordination and dexterity. ${ }^{20}$ This study has demonstrated that the measurement of grip strength should form a part of any adequate assessment battery. Furthermore, the procedure used in this study provides a brief method of plotting the course of intrinsic neurological recovery as it affects the arm. ${ }^{21}$ Frequent assessments of individual patients using this technique, provides an easy objective method of determining the rate of early or late recovery. This may prove useful in attempts to discover whether recovery is accelerated by increasing the intensity of physiotherapy.

Finally, this study has confirmed earlier findings ${ }^{1}$ that the absence of measurable grip by one month after stroke, indicates that there will be poor functional outcome. However, the Motoricity Index allowed more accurate prediction of outcome, and Bard and Hirschberg ${ }^{8}$ also found that patients who eventually gained full range of movement had visible movement at the shoulder, elbow or hand within the first month. It therefore seems that any assessment which records the beginnings of voluntary movement in the first four weeks will serve as a prognostic indicator. The particular value of grip strength assessment may be that it provides an all-or-none cut-off point for the clinician to use. Some proximal movement of the arm within the first four weeks is seen in some cases where there is no eventual return of useful function, whereas if there is detectable grip at one month, then the clinician can be reasonably certain that there will be at least rudimentary function five months later.

We gratefully acknowledge continued support by the Chest, Heart and Stroke Association.

We thank the patients and medical staff at Frenchay Hospital who made this study possible and Dr Derick Wade for his comments on the manuscript. 


\section{References}

1 Heller A, Wade DT, Wood VA, Sunderland A, Langton Hewer R, Ward E. Arm function after stroke: measurement and recovery over the first three months. J Neurol Neurosurg Psychiatry 1987;50:714-9.

2 Wade DT, Langton Hewer R, Wood VA, Skilbeck CE, Ismail HM. The hemiplegic arm after stroke: measurement and recovery. J Neurol Neurosurg Psychiatry 1983;46:521-4.

3 Sharpless JW. The nine-hole peg test of finger hand co-ordination for the hemiplegic patient. In: Sharpless JW, ed. Mossman's A Problem Oriented Approach to Stroke Rehabilitation. Springfield, Illinois: Charles C Thomas, 1982:420-3.

4 Lezak MD. Neuropsychological Assessment. 2nd ed. Oxford: Oxford University Press, 1983:529.

5 Bobath B. Adult Hemiplegia: evaluation and treatment. 2nd ed. London: William Heinemann Medical Books, 1978.

6 Carr JH, Shepherd R. Physiotherapy in Disorders of the Brain. London: Heinemann, 1980.

7 Twitchell TE. The restoration of motor function following hemiplegia in man. Brain 1951;74:443-80.

8 Bard G, Hirschberg GG. Recovery of voluntary motion in upper extremity following hemiplegia. Arch Phys Med Rehabil 1965; 46:567-72.

9 Bohannon RW. Relationship between static strength and various other measures in hemiparetic stroke patients. Int Rehabil Med 1987;8:125-8.

10 Bohannon RW. Weakness in the stroke patient: a review. In: Singleton M, Branch E, eds. Physical Therapy After Stroke: Pathologic Aspects and Clinical Management. Haworth Press,
1987;43-55.

11 Sunderland A. An intensive retraining programme for arm function after stroke. Int J Rehabil Res 1987;10:354.

12 Demeurisse G, Demol O, Rolaye E. Motor evaluation in vascular hemiplegia. Eur Neurol 1980;19:382-9.

13 Ashburn A. A physical assessment for stroke patients. Physiotherapy 1982;68:109-13.

14 Reitan RM, Davison LA. Clinical Neuropsychology: current status and applications. New York: Hemisphere, 1974.

15 Prescott RJ, Garraway WM, Akhtar AJ. Predicting functional outcome following acute stroke using a standard clinical examination. Stroke 1982;13:641-7.

16 Brunnstrom S. Movement Therapy in Hemiplegia. A Neurophysiological Approach. New York: Harper and Row, 1970.

17 Miller S, Hammond GR. Neural control of arm movement in patients following stroke. In: van Hoff MW, Mohn G, eds. Functional Recovery from Brain Damage. Amsterdam: Elsevier, 1981;259-74.

18 McComas AJ, Sica REP, Upton ARM, Aguilera N. Functional changes in motorneurones of hemiparetic patients. $J$ Neurol Neurosurg Psychiatry 1973;36:183-93.

19 Rosenfalck A, Andreassen S. Impaired regulation of force and firing pattern of single motor units in patients with spasticity. $J$ Neurol Neurosurg Psychiatry 1980;43:907-16.

20 Turton A, Fraser CM. A test battery to measure recovery of voluntary movement control following stroke. Int Rehabil Med 1986;8:74-8.

21 Wade DT, Langton Hewer R, Skilbeck CE, David RM. Stroke: $A$ Critical Approach to Diagnosis, Treatment and Management. London: Chapman and Hall, 1985:180-4. 